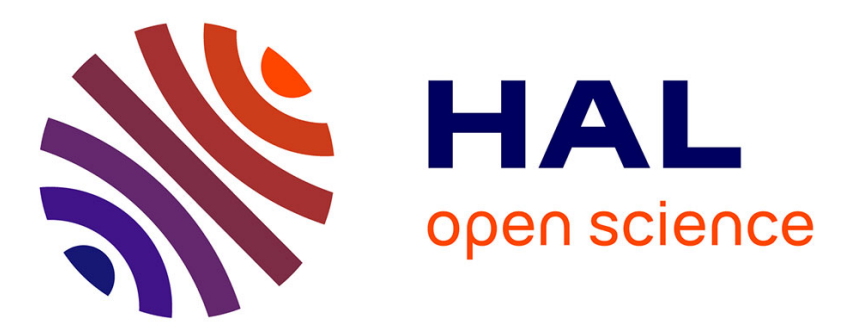

\title{
ESTIMATION OF SEX-AND AGE-RELATED SURVIVAL RATES IN A MICROTINE POPULATION
}

Emmanuel Paradis, Gérald Guedon, Roger Pradel

\section{To cite this version:}

Emmanuel Paradis, Gérald Guedon, Roger Pradel. ESTIMATION OF SEX-AND AGE-RELATED SURVIVAL RATES IN A MICROTINE POPULATION. Journal of Wildlife Management, 1993, 57 (1), pp.158. 10.2307/3809012 . ird-02062359

\section{HAL Id: ird-02062359 https://hal.ird.fr/ird-02062359}

Submitted on 8 Mar 2019

HAL is a multi-disciplinary open access archive for the deposit and dissemination of scientific research documents, whether they are published or not. The documents may come from teaching and research institutions in France or abroad, or from public or private research centers.
L'archive ouverte pluridisciplinaire HAL, est destinée au dépôt et à la diffusion de documents scientifiques de niveau recherche, publiés ou non, émanant des établissements d'enseignement et de recherche français ou étrangers, des laboratoires publics ou privés. 


\section{ESTIMATION OF SEX- AND AGE-RELATED SURVIVAL RATES IN A MICROTINE POPULATION}

EMMANUEL PARADIS, Laboratoire d'Eco-éthologie, Institut des Sciences de l'Evolution, Case

Courrier 64, Université de Montpellier II (U.S.T.L.), Place Eugène Bataillon, F-34095

Montpellier cédex 5, France

GERALD GUEDON, Délégation régionale ACTA, Maison de l'Agriculture de Vendée, Boulevard

Réaumur, F-85013 La Roche-sur-Yon cédex, France

ROGER PRADEL, Laboratoire de Biométrie, Centre d'Ecologie Fonctionnelle et Evolutive

(C.N.R.S.), route de Mende, BP 5051, F-34033 Montpellier cédex, France

Abstract: Little is known about the sex- and age-related survival rates of microtine rodents. Thus, we used probabilistic models and recent software developments to estimate survival rates in a Mediterranean pine vole (Microtus duodecimcostatus) population studied by capture-recapture. Goodness-of-fit tests revealed that erratics (voles caught only once) were captured during every trapping-session. Removal of the erratics from the data was necessary for application of the Jolly-Seber model. The model selected according to parsimony criteria, which assumes higher survival rate for juvenile males than juvenile females. Survival rates were higher among adults of both sexes than among juveniles, but there was no influence of sex on adult survival rate. These variations of survival rates can be related to demographic traits of Mediterranean pine vole (relative abundance in different habitats, local population dynamics). Our data also suggest that the regional abundance of the Mediterranean pine vole is determined by “source-sink dynamics”.

Key words: capture-recapture, individual variations, Mediterranean area, Microtus duodecimcostatus, parsimony, Pine vole, probabilistic models, survival rate 
In general, management of wild populations requires knowledge about population parameters, particularly survival rate of the individuals (Eberhardt 1985). The development of stochastic models of capture-recapture in the 1960's provided an analytical tool to population ecologists for the estimation of survival rates (Cormack 1964, Jolly 1965, Seber 1965). Recent developments have made these methods more flexible, more powerful, and more available to field ecologists (Seber 1986, Clobert et al. 1987, Pollock et al. 1990), and allowed differential estimation of survival rates for the individuals of a population relative to individual features (Pradel et al. 1990, Lebreton et al. 1992). This improvement is of particular interest for ecologists who face the problem of variability in survivorship within and among populations under study. Ignoring such variability can lead to wrong conclusions about the dynamics of a population (Johnson et al. 1986).

Several rodent species are agricultural pests. The Mediterranean pine vole occurs in some cultivated areas of the Mediterranean region where it sometimes causes dramatic agricultural damage. When a population is driven to extinction by snap-trapping or poisoning, recolonization of the area occurs rapidly, and undisturbed populations persist for many years. These observations indicate that migration may be critical in the population dynamics of the Mediterranean pine vole; undisturbed populations seem to function as source populations, and snap-trapping or poisoning artificially create sink populations. In this type of metapopulation, local population dynamics of source populations and dispersal are important in determining the regional abundance of the species (Pulliam 1988, Hanski and Gilpin 1991). Theoretical as well as empirical considerations indicate that dispersal is male-biased in populations of mammalian species such that females are mainly recruited in situ (Greenwood 1980, Dobson 1982, Pusey 1987). So, we could predict that males in source populations have a lower apparent survival rate than females. Here we test this hypothesis in a population of Mediterranean pine voles by studying variations of apparent survival rates between individuals. We could have attempted to measure dispersal directly, but this is quite difficult, and statistics for the analysis of dispersal patterns are not yet fully developed (Tonkyn and Plissner 1991). Because estimations of survival rates are motivated by testing biological hypotheses, modeling survival rates and fitting parsimonious models are appropriate analytical tools (Lebreton et al. 1992).

We thank J.-P. Airoldi, J. D. Nichols, and an anymous reviewer for their helpful comments on an early draft of the manuscript, and F. Catzeflis for encouraging us. We 
are indebted to Mr. Giammatei for allowing us access to his property. We also thank various people for their assistance in the field.

\section{METHODS}

The Mediterranean pine vole has a very narrow geographic distribution including Spain, Portugal, and southern France (where we studied a population in an apple orchard [4339’ N, 4¹1’ E]). Trapping-sessions were conducted every 3 months (Feb, May, Aug, and Nov) during 1989-1990 using Longworth traps baited with apple. Traps were distributed on a 1-ha area, along 6 parallel 5- $\times 100-\mathrm{m}$ strips divided into $25-\mathrm{m}^{2}$ quadrats. Up to 2 trap stations were arranged in each square, and each trap station contained 1, 2, or 3 traps oriented in the axis of a previously dug tunnel. In such habitats, home ranges have an elliptical shape (Pagano and Madison 1981, Fitzgerald and Madison 1983), so we spaced the strips regularly on the area (14 m between the edges of 2 strips) in such a way as to catch most of the animals. Traps were checked every 6 hours over a 42-hour period. When captured, animals were marked by toeclipping and ear-marking, reproductive condition was noted (males: testes scrotal or abdominal; females: pregnant, lactating, and vulva open or closed), and their mass was determined. We distinguished 2 age classes using a body-mass criterion: adults (> $17 \mathrm{~g}$ ), and juveniles ( $\leq 17 \mathrm{~g})$.

We used programs RELEASE 2.4 (Burnham et al. 1987) and SURGE 4.1 (Pradel and Lebreton 1991) to perform analysis of the data. RELEASE was used to estimate goodness-of-fit to test the validity of the assumptions made for the application of the Jolly-Seber model. These assumptions are: 1) the probability of capture is the same for all individuals (but may vary with time), 2) the survival rate is the same for all individuals (but may vary with time), 3) emigration is permanent (Begon 1983). We incorporated the results of the tests performed by RELEASE into a SURGE model. SURGE fits a probabilistic model chosen by the user to the capture-recapture data (histories of capture). The model computed with SURGE is specified by the user who chooses the variables influencing survival and/or recapture rates. For instance, survival and/or recapture rates can be age-dependent, and/or time-dependent, or constant over age and time, or influenced by a climatic variable, or related to some other environmental feature. The Jolly-Seber model is only a particular case of these models, for which both survival and recapture rates are time-dependent. Several data sets can be analyzed simultaneously, allowing incorporation of individual features (e.g., sex, 
genotypes, nest location, etc.) in estimation of survival and/or recapture rates. A large class of models can be computed that incorporate many sources of variation (age, time, sex, external factors, interactions between factors, etc). Maximum likelihood estimation of parameters (survival and recapture rates) is performed by program SURGE. Selection of models is the “critical” step of modeling capture-recapture data: we took into account both parsimony criteria and the biological significance of the models (Pradel et al. 1990, Lebreton et al. 1992). We compared models by likelihood ratio tests ( $\chi^{2}$-tests). Mean life-span for animals grown as adults is estimated as follows (provided they have a constant survival rate):

$$
-\mathrm{I} / \mathrm{ln} \hat{\phi}
$$

where: I = time between two occasions of capture, and $\hat{\phi}=$ estimated adult survival rate.

Raw data were structured into 4 data sets: male juveniles, female juveniles, male adults, and female adults (age determined at first capture).We analysed each data set separately or in association with $\geq 1$ other data set.

\section{RESULTS}

We trapped the population during 8 sessions (Feb 1989-Nov 1990) and caught 1,449 voles. The 4 data sets consisted of: 524 adult males, 531 adult females, 200 juvenile males, and 194 juvenile females. Fifteen animals were killed by the traps (for each data set: $5,4,4$, and 2 , respectively). We incorporated this mortality caused by the trapping into the SURGE analysis.

\section{Goodness-of-fit Tests}

Tests performed with male and female adult data sets led to the rejection of the JollySeber model $\left(\chi^{2} 20=88.683, P<0.0005\right.$, and $\chi^{2} 23=70.426, P<0.0005$, respectively). Detailed analysis of the intermediate tests (Burnham et al. 1987) showed that unmarked animals captured and marked at a given time have a lower probability of being recaught subsequently than animals marked before; but if they are re-caught, their subsequent recapture probability is not different from that of previously marked animals. This result led us to remove first captures from both data sets, so that animals caught only once are not taken into account in the corrected data. RELEASE tests 
performed with the corrected data showed complete homogeneity $\left(\chi^{2} 13=16.574, P=\right.$ 0.220 and $\chi^{2} 13=13.275, P=0.427$, for males and females, respectively). This result can be interpreted as being due to the capture of erratics (those caught only once), or to an increased mortality due to toe-clipping.

Tests performed with the male juvenile data led to the acceptance of the Jolly-Seber model $\left(\chi^{2} 16=17.001, P=0.386\right)$. Data on female juveniles were insufficient to perform chi square-tests. However, application of Fisher's exact tests also led to an acceptance of the Jolly-Seber model. Lack of disappearance of newly caught animals versus those previously caught (as observed for the adults) led us to reject the hypothesis of a lethal effect of the marking technique that was used and to assume that some erratic adults were continuously trapped in our population. To fit a model to the data, we used the corrected data with first captures removed for adults. Boutin and Krebs (1986) also addressed this problem of animals with single capture, which substantially decreased the Jolly-Seber estimates of survival rates in their study of snowshoe hares (Lepus americanus). However, they didn’t provide goodness-of-fit tests of the Jolly-Seber model to their data.

\section{Age and Sex Effects on Survival and Recapture Probabilities}

Although the Jolly-Seber model was accepted for the 4 data sets, we considered the possibility of an age effect in the analyses because it is a biologically reasonable hypothesis. An age effect can be masked by the time effect. A preliminary survey analysis of the juvenile data sets actually showed a trend of increasing survival with age.

First, we analyzed the data sets of adults separately to detect the influence of absolute age or time on survival rates and recapture rates. For both data sets, the hypothesis that survival and recapture rates were constant over absolute age and time was accepted $\left(\chi^{2} 24=21.032, P=0.6\right.$, and $\chi^{2} 24=21.602, P=0.6$, for males and females, respectively). "Absolute age" does not refer to the real age of the individuals, but to the time since first capture (Clobert et al. 1987); however, a high level of non-significance of the tests evidences a homogeneity of survival and recapture rates within a absolute cohort.

Second, we constructed a model to analyze the 4 age and sex data sets together. The time required for the Mediterranean pine vole to reach adulthood is about 2.5 months (Pascal et al. 1988). We assumed that juveniles become adults during the 3 months 
between 2 trapping sessions (only 1 animal out of 388 retained juvenile characteristics between 2 periods), so the survival rate changed after the second capture for animals caught as juveniles and was assumed to be the same as for animals caught as adults. Potential sources of variation for survival and recapture rates were sex, age class, and the interactions between these 2 factors (Table 1). We graphically present the selection process (Fig. 1). The survival rate of adults is greater than that of juveniles (Table 2); for juveniles, survival rate is greater among males than among females. The recapture rate is not influenced by sex or age class (Table 2). The estimated adult mean life span is 7.75 months.

\section{DISCUSSION}

There are 2 main applications for probabilistic models: estimating population sizes and estimating survival rates. The first application in small mammal capture-recapture studies was discussed by Jolly and Dickson (1983), Nichols and Pollock (1983), and Boonstra (1985). Estimation of survival rates in small mammal populations is not yet as widespread. Nichols and Conley (1982), Boonstra (1985) and Nichols and Pollock (1990) used the Jolly-Seber model; however, significance of time-dependence was not tested in these studies. Anyway, simulation and field studies have demonstrated that Jolly-Seber estimators perform better than estimators based on enumeration methods (Nichols and Pollock 1983, Boonstra 1985, Boutin and Krebs 1986).

Our study further emphasized the need for flexibility in the analysis of capturerecapture data. The demonstration of a difference in survival between juveniles and adults and between females and males among juveniles was made possible by the use of parsimonious models without time effect, and the simultaneous treatment of different data sets corresponding to different categories of individuals sharing some parameters. In this context, the biologically relevant question is addressed without interference from background noise (here time effect) and with all the information available. As a consequence, the tests are more powerful.

The results of the goodness-of-fit tests to the Jolly-Seber model with the uncorrected adult data sets (resident individuals with erratics) could have been interpreted within the framework provided by Brownie and Robson (1983), where individuals have a lower survival after the first observation than after reobservation (it is unimportant whether the first observation differs from reobservations because physical capture takes place only at this time as occurs in Brownie-Robson model, or because toe-clipping occurs at 
this moment as in our study). Yet the results of the goodness-of-fit tests to the JollySeber model with the uncorrected juvenile data sets led us to reject this assumption, and to infer the presence of erratics in the adult data sets. In this situation, use of the Brownie-Robson model would be incorrect. It is noteworthy that the goodness-of-fit test for the Brownie-Robson model (which is exactly one of the tests performed by RELEASE [test 3.SR, Burnham et al. 1987]) tests for a difference of destiny (subsequently recaught or not) between the marked individuals and the unmarked ones. So, the hypothesis of a decrease in survival after the first capture is not the only possible biological interpretation.

Our analyses allow us to draw conclusions about the structure of the studied population without prior knowledge of social behavior. This is possible because sources of heterogeneity in the data can be related to individual features (residence time, age, or sex). The low juvenile survival rate in our population of Mediterranean pine vole must be related to high mortality and/or dispersal for juveniles both sexes. An increase of survival rate with maturation seems to be a pattern common to birds and mammals (Loery et al. 1987). We must note that voles became adults during the 3 months between the 2 trapping sessions (Pascal et al. 1988). The adult survival rate is not influenced by absolute age, this apparently excludes phenomena like senescence or increased survivorship with age.

Our most surprising result was the higher survival rate of males among juveniles. Some reviews (Greenwood 1980, Dobson 1982, Pusey 1987) showed that dispersal by male juveniles is predominant among mammalian species, and some very recent studies (Boonstra et al. 1987; Boonstra and Craine 1988; Ims 1989, 1990; Sandell et al. 1990) support this fact about voles. With the method we used, dispersal and mortality cannot be distinguished, so it was not possible to address the question of philopatry. However, dispersal in small mammal species may be more complex than previously suggested (e.g., Jones 1988; Jones et al. 1988; Sandell et al. 1990, 1991). We must also be aware that method issues can affect our perceptions of dispersal. For instance, some studies have focused on distances moved by dispersers without measuring mortality rates (cf. Jones 1988). Recapture probability (as estimated by probabilistic models) is sometimes very low (e.g., Lefebvre et al. 1982), and we believe that this must be taken into account in studies of population ecology of small mammals.

\section{RESEARCH IMPLICATIONS}


Our analysis of data was directed by the use of parsimony in the models and the introduction of heterogeneity only when necessary. This rule was advantageous because parsimonious models have fewer problems of identifiability of parameters (Sandland and Kirkwood 1981), more accurate estimation of the parameters can be achieved (Jolly 1982), and it is possible to test biological significance of the models via likelihood ratio tests (Lebreton et al. 1992).

Our results seem to confirm that the regional abundance of the Mediterranean pine vole is determined by “source-sink” dynamics (Pulliam 1988). The colonizers are adults without established home ranges that appeared as erratics in our study. Most of the juveniles born in a source population die or disperse before breeding. So, most of reproductive output is due to resident individuals in the source populations.

\section{LITERATURE CITED}

Begon, M. 1983. Abuses of mathematical techniques in ecology: applications of Jolly’s capture-recapture method. Oikos 40:155-158.

Boonstra, R. 1985. Demography of Microtus pennsylvanicus in southern Ontario: enumeration versus Jolly-Seber estimation compared. Can. J. Zool. 63:11741180.

Boonstra, R., and I. T. M. Craine. 1988. Similarity of residence times among Microtus littermates: importance of sex and maturation. Ecology 69:1290-1293.

Boonstra, R., C. J. Krebs, M. S. Gaines, M. L. Johnson, and I. T. M. Craine. 1987. Natal philopatry and breeding systems in voles (Microtus spp.). J. Anim. Ecol. 56:655673.

Boutin, S., and C. J. Krebs. 1986. Estimating survival rates of snowshoe hares. J. Wildl. Manage. 50:592-594.

Brownie, C., and D. S. Robson. 1983. Estimation of time-specific survival rates from tag-resighting samples: a generalization of the Jolly-Seber model. Biometrics 39:437-453.

Burnham, K. P., D. R. Anderson, G. C. White, C. Brownie, and K. H. Pollock. 1987. Design and analysis methods for fish survival experiments based on releaserecapture. Am. Fish. Soc. Monogr. 5. Bethesda, Md. 437pp.

Clobert, J., J.-D. Lebreton, and D. Allainé. 1987. A general approach to survival rate estimation by recaptures or resightings of marked birds. Ardea 75:133-142.

Cormack, R. M. 1964. Estimates of survival from the sighting of marked animals. 
Biometrika 51:429-438.

Dobson, F. S. 1982. Competition for mates and predominant juvenile male dispersal in mammals. Anim. Behav. 30:1183-1192.

Eberhardt, L. L. 1985. Assessing the dynamics of wild populations. J. Wildl. Manage. 49:997-1012.

Fitzgerald, R. W., and D. M. Madison. 1983. Social organization of a free-ranging population of pine voles, Microtus pinetorum. Behav. Ecol. Sociobiol. 13:183187.

Greenwood, P. J. 1980. Mating systems, philopatry and dispersal in birds and mammals. Anim. Behav. 28:1140-1162.

Hanski, I., and M. Gilpin. 1991. Metapopulation dynamics: brief history and conceptual domain. Pages 3-16 in M. Gilpin, and I. Hanski, eds. Metapopulation dynamics: empirical and theoretical investigations. Academic Press, London.

Ims, R. A. 1989. Kinship and origin effects on dispersal and space sharing in Clethrionomys rufocanus. Ecology 70:607-616.

Ims, R. A. 1990. Determinants of natal dispersal and space use in grey-sided voles, Clethrionomys rufocanus: a combined field and laboratory experiment. Oikos 57:106-113.

Johnson, D. H., K. P. Burnham, and J. D. Nichols. 1986. The role of heterogeneity in animal population dynamics. Pages 1-15 in Biometric Society, Proc. 13th Int. Biom. Conf.. Univ. of Washington, Seattle.

Jolly, G. M. 1965. Explicit estimates from capture-recapture data with both death and immigration-stochastic models. Biometrika 52:225-247.

Jolly, G. M. 1982. Mark-recapture models with parameters constant in time. Biometrics 38:301-321.

Jolly, G. M., and J. M. Dickson. 1983. The problem of unequal catchability in markrecapture estimation of small mammal populations. Can. J. Zool. 61:922-927.

Jones, W. T. 1988. Density-related changes in survival of philopatric and dispersing kangaroo rats. Ecology 69:1474-1478.

Jones, W. T., P. M. Waser, L. F. Elliot, N. E. Link, and B. B. Bush. 1988. Philopatry, dispersal, and habitat saturation in the banner-tailed kangaroo rat, Dipodomys spectabilis. Ecology 69:1466-1473.

Lebreton, J. D., K. P. Burnham, J. Clobert, and D. R. Anderson. 1992. Modeling survival and testing biological hypotheses using marked animals: a unified 
approach with case studies. Ecol. Monogr. 62:67-118.

Lefebvre, L. W., D. L. Otis, and N. R. Holler. 1982. Comparison of open and closed models for cotton rat population estimates. J. Wildl. Manage. 46:156-163.

Loery, G., K. H. Pollock, J. D. Nichols, and J. E. Hines. 1987. Age-specificity of blackcapped chickadee survival rates: analysis of capture-recapture data. Ecology 68:1038-1044.

Nichols, J. D., and W. Conley. 1982. Active-seasonal dynamics of a population of Zapus hudsonius in Michigan. J. Mammal. 63:422-430.

Nichols, J. D., and K. H. Pollock. 1983. Estimation methodology in contemporary small mammal capture-recapture studies. J. Mammal. 64:253-260.

Nichols, J. D., and K. H. Pollock. 1990. Estimation of recruitment from immigration versus in situ reproduction using Pollock’s robust design. Ecology 71:21-26.

Pagano, R. E., and D. M. Madison. 1981. Seasonal variations in movements and habitat use by pine and meadow voles. Pages 35-44 in R. E. Byers, ed. Proc. fifth eastern pine and meadow vole symposium, Gettysburg, Pa., March 4-5, 1981.

Pascal, M., J.-P. Damange, P. Douville, and G. Guédon. 1988. Recherche de critères d’âge chez le campagnol provençal Pitymys duodecimcostatus (De SélysLongchamps, 1839). Mammalia 52:85-91.

Pollock, K. H., J. D. Nichols, C. Brownie, and J. E. Hines. 1990. Statistical inference for capture-recapture experiments. Wildl. Monogr. 107:1-97.

Pradel, R., J. Clobert, and J.-D. Lebreton. 1990. Recent developments for the analysis of capture-recapture multiple data sets. An example concerning two Blue Tit populations, Parus caeruleus. The Ring 13:193-204.

Pradel, R., and J.-D. Lebreton. 1991. User’s manual for program SURGE version 4.1. Mimeographed document, C.E.P.E./C.N.R.S. BP 5051, 34033 Montpellier cédex, France 35pp.

Pulliam, H. R. 1988. Sources, sinks, and population regulation. Am. Nat. 132:652-661.

Pusey, A. E. 1987. Sex-biased dispersal and inbreeding avoidance in birds and mammals. Trends Ecol. Evol. 2:295-299.

Sandell, M., J. Agrell, S. Erlinge, and J. Nelson. 1990. Natal dispersal in relation to population density and sex ratio in the field vole, Microtus agrestis. Oecologia 83:145-149.

Sandell, M., J. Agrell, S. Erlinge, and J. Nelson. 1991. Adult philopatry and dispersal in the field vole Microtus agrestis. Oecologia 86:153-158. 
Sandland, R. L., and G. P. Kirkwood. 1981. Estimation of survival in marked populations with possibly dependent sighting probabilities. Biometrika 68:531541.

Seber, G. A. F. 1965. A note on the multiple recapture census. Biometrika 52:249-259.

Seber, G. A. F. 1986. A review of estimating animal abundance. Biometrics 42:267_ 292.

Tonkyn, D. W., and J. H. Plissner. 1991. Models of multiple dispersers from the nest: predictions and inference. Ecology 72:1721-1730. 
Table 1. Description of the models used to study Mediterranean pine vole population, southern France, 1989-90.

\begin{tabular}{|l|l|l|}
\hline Model $^{\mathrm{a}}$ & Notation $^{\mathrm{b}}$ & Description \\
\hline A & $\phi_{a+s+a . s, p a+s+a . s}$ & $\begin{array}{l}\text { All 4 categories have different survival and } \\
\text { recapture probabilities. }\end{array}$ \\
\hline B & $\phi_{a+s+a . s, p}$ & $\begin{array}{l}\text { All } 4 \text { categories have different survival } \\
\text { probabilities; recapture rate is constant. }\end{array}$ \\
\hline C & $\phi_{a+s, p}$ & $\begin{array}{l}\text { Age and sex effects on survival are } \\
\text { cumulative; recapture rate is constant. }\end{array}$ \\
\hline D & $\phi_{a+a . s, p}$ & $\begin{array}{l}\text { Adults of both sexes have the same survival } \\
\text { probabilities, female juveniles and male } \\
\text { juveniles differ in survival between them } \\
\text { and from adults; recapture rate is constant. }\end{array}$ \\
\hline E & $\phi_{a . s, p}$ & $\begin{array}{l}\text { Same survival for all groups except female } \\
\text { juveniles; recapture rate is constant. }\end{array}$ \\
\hline
\end{tabular}

${ }^{a}$ Models consider different patterns of variation in survival probabilities $(\phi)$ and recapture probabilities $(p)$ between four categories of individuals.

${ }^{\mathrm{b}}$ Male adults are taken as reference; $(a)$ is the juvenile effect, $(s)$ the female effect, $(a . s)$ is an effect limited to female juveniles. 
Table 2. Survival rates and recapture rates of Mediterranean pine voles estimated using model D (Table 1), southern France, 1989-90.

\begin{tabular}{|l|l|c|c|c|c|}
\hline Age class & Sex & \multicolumn{2}{|c|}{ Survival rate } & \multicolumn{2}{c|}{ Recapture rate } \\
\hline \multirow{2}{*}{ Ad } & & $\hat{\phi}$ & SE & $\hat{p}$ & SE \\
\hline \multirow{2}{*}{ Juv } & M & 0.679 & $0.022^{\mathrm{a}}$ & 0.575 & $0.030^{\mathrm{b}}$ \\
\cline { 2 - 6 } & F & 0.679 & 0.022 & 0.575 & 0.030 \\
\cline { 2 - 6 } & $\mathrm{M}$ & 0.358 & 0.048 & 0.575 & 0.030 \\
\cline { 2 - 6 } & F & 0.212 & 0.038 & 0.575 & 0.030 \\
\hline
\end{tabular}

${ }^{a}$ Estimates apply to both males and females.

${ }^{\mathrm{b}}$ Estimates apply to the whole population. 
Fig. 1. Modeling of capture-recapture data for Mediterranean pine vole. Model D is selected on the basis of a minimal Akaike's information criterion (AIC) and compared with model B and model $\mathrm{E}$ by likelihood ratio tests ( $\chi^{2}$-tests). The AIC is a practical criterion to compare different models fitted to the same data. It is a compromise between fit and parsimony as shown by its formula: $A I C=\mathrm{Dev}+2 n p$, where $\mathrm{Dev}$ is a measure of fit (the deviance), $n p$ is the number of identifiable parameters in the model. In our case, the software we used (SURGE) gives only a relative deviance (deviance up to a constant). This is sufficient to compare the models and choose the one with the lower AIC. For further technical details see Lebreton et al. (1992). n.s. $=P>0.05$, $* *=$ $0.01<P<0.025$, *** $=P<0.001$. 


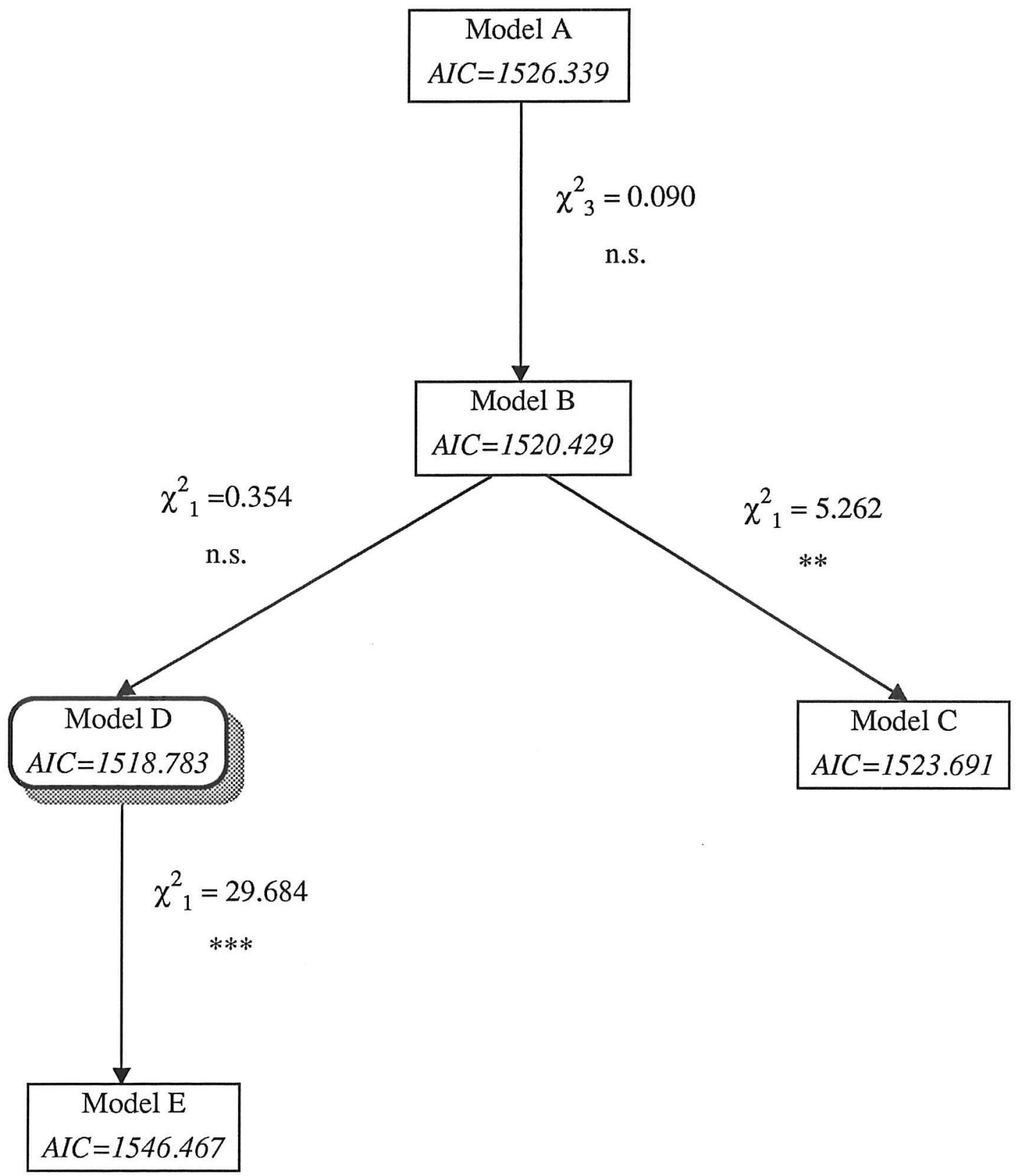

